\title{
The Progression of Serum Prorenin Concentration during Pregnancy
}

\section{Yukiko Mikami ${ }^{1 *}$, Tatsuya Narita1, Yasushi Takai ${ }^{1}$, Kazunori Baba ${ }^{1}$, Hiroyuki Seki ${ }^{1}$ and Kikumi Matsuoka ${ }^{2}$}

${ }^{1}$ Department of Obstetric and Gynecology, Saitama Medical Center, Saitama Medical University, Saitama, Japan

${ }^{2}$ Department of Biomedical Sciences, Saitama Medical Center, Saitama, Japan

\begin{abstract}
Objective: An association between the renin-angiotensin system and the pathogenesis of pregnancy-induced hypertension has been reported. The prorenin receptor was discovered in 2002, and Wanatabe et al. reported that women with plasma soluble prorenin receptor concentrations above the 75th percentile at delivery had a significantly increased risk of preeclampsia. We evaluated serum prorenin concentrations during pregnancy, and we assessed the incidence of pregnancy-induced hypertension.

Methods: We measured serum prorenin concentrations in 430 pregnant women (565 samples). Regression analysis was performed to determine the associations between the serum prorenin level and maternal/neonatal complications.

Results: The serum prorenin concentration and gestational age had a positive correlation in non-pregnancyinduced hypertension in women with singleton pregnancies (Spearman rank-correlation coefficient, $-0.215: p<0.0001$ ). The serum prorenin concentration in women with multiple pregnancies was significantly higher than that in women with singleton pregnancies (multiple linear regression analysis, $\mathrm{p}<0.0001$ ). Low prorenin levels in the third trimester ( $\leq 20.1$ percentile) were significantly associated with pregnancy-induced hypertension (adjusted odds ratio, 18.16: 95\% confidential interval, 1.95-412.41: $\mathrm{p}=0.0107$ ).
\end{abstract}

Conclusion: The serum prorenin levels during pregnancy may be adversely correlated with the prorenin receptor, and low prorenin levels during late pregnancy were significantly associated with pregnancy-induced hypertension.

Keywords: Prorenin; Preeclampsia; Gestational hypertension; Renin-angiotensin system; Pregnancy-induced hypertension; Prorenin receptor; Risk of preeclampsia; Incidence of pregnancy-induced hypertension; Blood pressure

Abbreviations: PIH: Pregnancy-Induced Hypertension; RAS: Renin-Angiotensin System; BP: Blood Pressure; AT2: Angiotensin 2; (P) RR: Prorenin Receptor; PR: Prorenin; BMI: Body Mass Index; GDM: Gestational Diabetes Millitus

\section{Introduction}

Pregnancy-Induced Hypertension (PIH), which includes preeclampsia and gestational hypertension, occurs in 3-5\% of pregnant women, and it can cause maternal death, premature delivery, and fetal growth restrictions [1]. Various studies have identified the etiology and pathology of $\mathrm{PIH}$, and it is clear that anti-angiogenesis factors play an important role.

The Renin Angiotensin System (RAS) also has an important role in hypertension: it maintains the constancy of Blood Pressure (BP) during pregnancy, which increases the cardiac output and circulating plasma volume [2]. Patients with PIH are sensitive to the pressor effects of Angiotensin 2 (AT2) compared to normotensive pregnant women $[3,4]$, and Gant et al. reported that an AT2 infusion test may predict the onset of preeclampsia [2], suggesting that the RAS is associated with the pathogenesis of PIH. The (Pro) Renin Receptor [(P)RR], a new component of the RAS, was discovered by Nguyen ftable in 2002 [5]. Wanatabe et al. reported that pregnant women with Plasma-Soluble (P) $\mathrm{Rr}[\mathrm{s}(\mathrm{P}) \mathrm{RR}]$ concentrations above the $75^{\text {th }}$ percentile at delivery had a significantly increased risk of preeclampsia [6]. In addition, RAS may have an important role in fetal development $[7,8]$, and tissue RAS may be crucial for placentation and the pathogenesis of PIH [9]. Since Prorenin (PR) combined with (P) RR activates the tissue RAS, we evaluated the serum $P R$ concentration during pregnancy to determine whether PR is also associated with PIH.

\section{Materials and Methods}

This prospective study included 430 pregnant Japanese women who visited the Center of Maternal Fetal and Neonatal Medicine of the Saitama Medical Center at the Saitama Medical University from April to August 2012. Written informed consent was obtained from all patients, and the study protocol was approved by the institution's ethics committee of the Saitama Medical Center, Saitama Medical University (Saitama, Japan).

Blood samples were obtained at a routine blood testing during prenatal checkup, and 565 samples were obtained. We divided the samples by gestational age. The first trimester was before 14 weeks 0 days gestation: the second trimester was between 14 weeks 0 days and 27 weeks 6 days: and the third trimester was 28 weeks 0 days or later. The serum PR concentration was examined using the direct enzyme-linked immunosorbent assay (Innovative Research Inc., Novi, MI, USA) in our center. We performed two assays for 1 sample and calculated the mean.

BPs was measured using an automated sphygmomanometer at every routine prenatal checkup. After resting, patients were made to sit with their right arm at their heart level.

*Corresponding author: Yukiko Mikami, Department of Obstetrics and Gynecology, Saitama Medical Center, Saitama Medical University, 1981 Kamoda, Kawagoe, Saitama, 350-3550, Japan, Tel: 81-49-228-3681: Fax: 81-49-226-1495: E-mail: ymikami@saitama-med.ac.jp

Received June 13, 2014: Accepted July 11, 2014: Published July 20, 2014

Citation: Mikami Y, Narita T, Takai Y, Baba K, Seki H, et al. (2014) The Progression of Serum Prorenin Concentration during Pregnancy. J Hypertens 3: 166. doi:10.4172/2167-1095.1000166

Copyright: @ 2014 Mikami Y, et al. This is an open-access article distributed under the terms of the Creative Commons Attribution License, which permits unrestricted use, distribution, and reproduction in any medium, provided the original author and source are credited. 
PIH was defined using the definition and classification proposed by the Japan Society for the Study of Hypertension in Pregnancy [10] (i.e., a BP of $\geq 140 / 90 \mathrm{mmHg}$ with or without proteinuria ( $\geq 300 \mathrm{mg}$ of protein in a 24 -hr urine specimen) after 20 weeks gestation in a patient with neither hypertension nor proteinuria prior to pregnancy). Earlyonset PIH was defined as the presentation of hypertension before 32 weeks of gestation.

Regression analysis was used to determine the association between serum PR level and maternal complications. Statistical analysis was performed by JMP 10 (SAS Institute, Inc., Cary, NC), and a $p<0.05$ was considered statistically significant.

\section{Results}

The clinical characteristics and gestational complications of the study participants are shown in Table 1. Thirty-six patients presented with PIH. Multivariate analyses of the serum PR levels are shown in Table 2. The significant effective factors for the PR concentration were gestational age at blood sampling, singleton pregnancy, and kidney disease, and PIH had a stronger influence on the PR level.

Figure 1 shows the correlation between PR concentration and gestational age at blood sampling in non-PIH, singleton pregnancy patients. There was a negative correlation between them (Spearman rack correlation coefficient, $-0.2145: \mathrm{p}<0.0001)$. Among the trimesters, PR levels were significantly higher in the first trimester than in the later trimesters. Additionally, in the non-PIH multiple pregnancy

\begin{tabular}{|c|c|}
\hline \multicolumn{2}{|l|}{ Baseline characteristics } \\
\hline Age, year (median [range]) & $35(16-47)$ \\
\hline BMI before pregnancy (median [range]) & $21.4(14.4-43.3)$ \\
\hline Gestational age at delivery (median [range]) & $\begin{array}{l}38 \text { weeks } 2 \text { days ( } 16 \text { weeks } 0 \\
\text { day- } 41 \text { weeks } 3 \text { days) }\end{array}$ \\
\hline \multicolumn{2}{|l|}{ Number of fetuses } \\
\hline Singleton & $370(86)$ \\
\hline Twin & $59(13.7)$ \\
\hline Triplet & $1(0.2)$ \\
\hline \multicolumn{2}{|l|}{ Parity } \\
\hline Primipara & $238(55.3)$ \\
\hline Multipara & $192(44.7)$ \\
\hline \multicolumn{2}{|l|}{ Complicating disease } \\
\hline Hypertension & $23(5.3)$ \\
\hline $\begin{array}{l}\text { Diabetes mellitus/Gestational diabetes } \\
\text { mellitus }\end{array}$ & $18(4.2)$ \\
\hline Thyroid disease & $18(4.2)$ \\
\hline Psychological disorder & $16(3.7)$ \\
\hline Kidney disease & $11(2.6)$ \\
\hline Collagen disease & $7(1.6)$ \\
\hline \multicolumn{2}{|l|}{ Gestational complications } \\
\hline Pregnancy-induced hypertension & $36(8.4)$ \\
\hline Early onset & $2 / 36(5.5)$ \\
\hline Late onset & $31 / 36(86.1)$ \\
\hline Postpartum & $3 / 36(8.3)$ \\
\hline Intrauterine fetal death & $7(1.62)$ \\
\hline \multicolumn{2}{|l|}{ Small for gestational age* } \\
\hline Singleton & $25(6.8)$ \\
\hline Multiple pregnancy (both) & $5(8.3)$ \\
\hline Multiple pregnancy (one of the pair) & $12(20)$ \\
\hline Placenta previa & $3(0.8)$ \\
\hline
\end{tabular}

*Defined as an infant whose birth weight is $<-1.5$ standard deviations All values are number (percentage), except where indicated

Table 1: Baseline and gestational characteristics of the study participants.

\begin{tabular}{|l|c|c|c|c|}
\hline Factor & Coefficient estimate & $95 \% \mathrm{Cl}$ & t ratio & $\mathrm{p}$-value \\
\hline $\begin{array}{l}\text { Gestational age } \\
\text { at blood sampling }\end{array}$ & -0.049 & -0.067 to -0.031 & -5.31 & $<0.0001$ \\
\hline Single pregnancy & -0.570 & -0.822 to -0.319 & -4.45 & $<0.0001$ \\
\hline Kidney disease & 0.597 & 0.05 to 1.14 & 2.16 & 0.031 \\
\hline PIH & -0.339 & -0.671 to -0.007 & -2.01 & 0.0455 \\
\hline ART & -0.204 & -0.433 to 0.319 & -1.74 & 0.0823 \\
\hline Hypertension & -0.321 & -0.714 to 0.071 & -1.61 & 0.1085 \\
\hline Maternal age & 0.008 & -0.029 to 0.046 & 0.42 & 0.6718 \\
\hline Primipara & 0.012 & -0.163 to 0.189 & 0.14 & 0.89 \\
\hline $\begin{array}{l}\text { BMI before } \\
\text { pregnancy }\end{array}$ & -0.002 & -0.038 to 0.034 & -0.10 & 0.9204 \\
\hline (G)DM & -0.005 & -0.461 to 0.451 & -0.02 & 0.9831 \\
\hline
\end{tabular}

Cl: Confidence Interval; PIH: Pregnancy-induced Hypertension; ART: Assisted Reproductive Technology; BMI: Body Mass Index; DM: Diabetes Mellitus; (G)DM Gestational Diabetes Mellitus. The factors of statistical significance are in boldfaced type

Table 2: Multivariate analysis of the serum PR level during pregnancy.

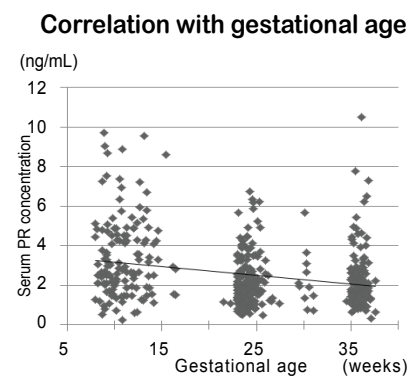

Spearman rank correlation coefficient $-0.2145 ; p<0.0001^{*}$

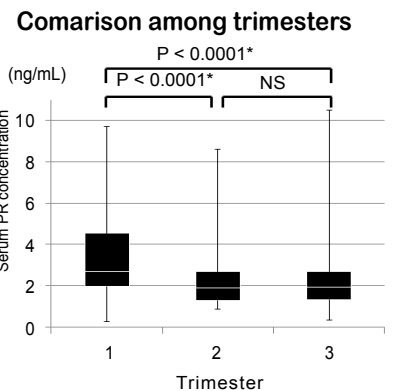

Kruskal-Wallis test, $p<0.0001^{*}$; NS, not significant
Figure 1: The correlation between serum Prorenin (PR) concentration and gestational age (non-pregnancy-induced hypertensive, singleton pregnancy patients).

patients, there was a negative correlation between gestational age and PR concentration (Spearman rank correlation coefficient, -0.2606: $\mathrm{p}=0.0346$ ) (Figure 2).

The serum PR concentrations were significantly higher in patients with multiple pregnancies than in patients with singleton pregnancies (covariance analysis, $\mathrm{p}<0.0001$ ), especially in the second trimester for the non-PIH patients (Figure 3).

Univariate analyses showed a significant association between low serum PR concentrations in the first trimester and elevated systolic and diastolic BPs at 32 weeks of gestational age $(\mathrm{p}=0.002$ and $\mathrm{p}=0.015$, respectively) and systolic $B P$ at 36 weeks of gestational age $(\mathrm{p}=0.029)$. However, in the multivariate analysis adjusted for age, Body Mass Index (BMI) before pregnancy, comorbidities (i.e., hypertension, Gestational Diabetes Mellitus (GDM), and kidney disease), parity, and multiple pregnancies showed no significant correlation between the serum PR concentration and BP.

Multivariate logistic regression analysis was performed to examine the association between serum PR concentrations and PIH for each trimester. Multivariate models were adjusted for age, parity, BMI before pregnancy, comorbidities (i.e., kidney disease, hypertension, and GDM), assisted reproductive technology, and multiple pregnancies). This analysis showed that low PR levels during the third trimester were significantly associated with PIH (Table 3a).

The receiver operating characteristic (ROC) curve analysis for 


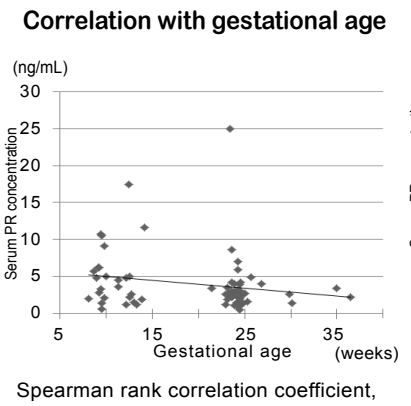

Spearman rank correlation coefficient $-0.2606 ; p=0.0346^{*}$

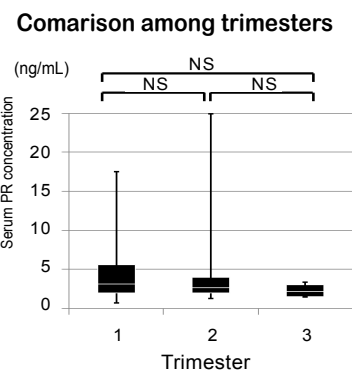

Kruskal-Wallis test, $p=0.4679$; NS, not significant

Figure 2: The correlation between serum prorenin (PR) concentration and gestational age (non-pregnancy-induced hypertensive, multiple pregnancy patients).

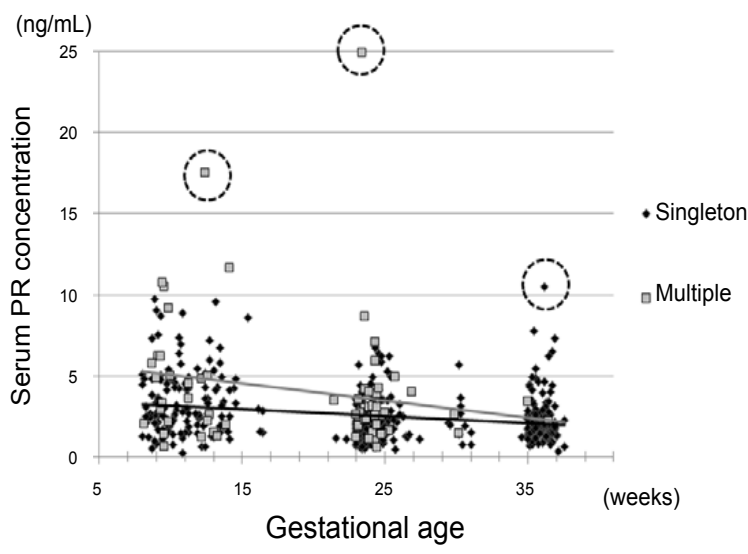

Figure 3: Serum Prorenin (PR) concentration and gestational age (singleton pregnancy versus multiple pregnancies).

\begin{tabular}{|l|c|c|c|c|}
\hline Gestational period & Total, $\mathbf{n}$ & $\mathbf{P I H}, \mathbf{n}(\mathbf{\%})$ & Adjusted OR* (95\% CI) & p-value \\
\hline First trimester & 169 & $21(12.4)$ & $0.757(0.517-1.01)$ & 0.0605 \\
\hline Second trimester & 256 & $15(5.9)$ & $0.893(0.597-1.121)$ & 0.4142 \\
\hline Third trimester & 140 & $6(4.3)$ & $0.274(0.054-0.937)$ & 0.0377 \\
\hline
\end{tabular}

OR: Odds Ratio; Cl: Confidence Interval

*Odds ratio, in which PIH develops when the plasma PR concentration increases by $1 \mathrm{ng} / \mathrm{mL}$

Table 3a: Multivariate logistic regression analysis of the association between serum prorenin concentration and pregnancy-induced hypertension $(\mathrm{PIH})$.

the predictors of PIH is shown in Figure 4. The area under the ROC curve for the PR concentration was the second largest after BMI before pregnancy. The cutoff serum PR concentration was $1.279 \mathrm{ng} / \mathrm{mL}(20.1$ percentile), as determined from this ROC curve. The adjusted odds ratio for $\mathrm{PIH}$ was 18.16 when the serum PR concentration was $\leq 1.279$ $\mathrm{ng} / \mathrm{mL}$ during the third trimester. The sensitivity, specificity, positive predictive value, and negative predictive value are also shown in Table $3 \mathrm{~b}$.

\section{Discussion}

The present study demonstrated the association between PR levels and pregnancy: First, the serum PR concentration showed a significant negative correlation with gestational weeks, and serum PR levels in patients with multiple pregnancies were significantly higher than in those in patients with singleton pregnancies, especially during early pregnancy. Second, there was no significant correlation between serum

PR concentration and BP. Third, low serum PR levels during the third trimester were significantly associated with $\mathrm{PIH}$.

Compared to the decreased s(P)RR levels during pregnancy, as reported by Watanabe et al. [4], the serum PR levels during pregnancy showed contrasting results, that is, increased. Plasma $s(\mathrm{P}) \mathrm{RR}$ levels increased gradually from early pregnancy to delivery and were higher in twin pregnancies at delivery. There was a significant association between high plasma s(P)RR levels at delivery and PIH. However, there was a difference in its association with BP. High plasma $s(\mathrm{P})$ $\mathrm{RR}$ levels during early pregnancy can predict elevated $\mathrm{BP}$ later in pregnancy: however, we were not able to detect a significant association between the serum PR levels and BP. We thought that the serum PR concentration may have less influence on $\mathrm{BP}$ regulation. It was assumed that the decrease in peripheral vascular resistance decreased BP after the second trimester due to a physiological change from pregnancy, because the vascular sensitivity to the pressor effects of AT2 decreases during pregnancy [2]. Our findings on the association between serum PR levels and BP may be related to these issues.

In Figures 2 and 3 there are a few outliers (shown in Figure 3 as the circle of the dotted line). They had a common point that repeat caesarean section but PR level of the patients of repeat caesarean section did not show clear trend, then we thought that probably the abnormal high PR concentration was the error that occurred in processes such as the specimen processing and it is more likely to be a simple coincidence.

From the present study findings, we thought that serum PR

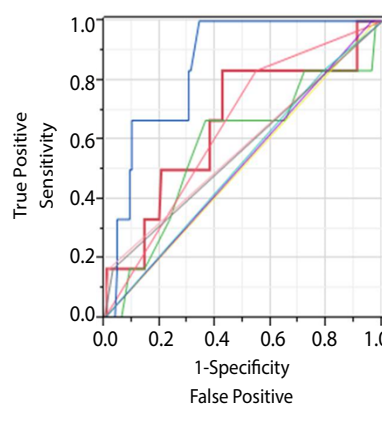

\begin{tabular}{|c|c|}
\hline Predictor & $\begin{array}{c}\text { Area umdter } \\
\text { the courvere }\end{array}$ \\
\hline BMl before pregnancy & 0.8491 \\
\hline Prorenin at $3^{\text {rd }}$ trimester & 0.6559 \\
\hline Parity & 0.6439 \\
\hline Maternal age & 0.5808 \\
\hline Kidney disease & 0.5758 \\
\hline Multiple pregnancy & 0.5682 \\
\hline ART & 0.5227 \\
\hline DM/GDM & 0.5189 \\
\hline Hypertension & 0.5114 \\
\hline
\end{tabular}

The cutoff concentration of plasma PR was $1.279 \mathrm{ng} / \mathrm{mL}(20.1$ percentile)

BMI, body mass index; ART, assisted reproductive technology; DM, diabetes mellitus; GDM, gestatinal diabetes mellitus

Figure 4: The receiver operating characteristic curve analysis for the predictors of pregnancy-induced hypertension.

\begin{tabular}{|l|l|r|}
\hline & Adjusted OR $(95 \% \mathrm{Cl})$ & P-value \\
\hline $\begin{array}{l}\mathrm{PR} \leq 1.279 \mathrm{ng} / \mathrm{mL} \text { during the third } \\
\text { trimester }\end{array}$ & $18.16(1.95-412.41)$ & 0.0107 \\
\hline
\end{tabular}

OR: Odds Ratio; $\mathrm{Cl}$ : Confidence Interval

\begin{tabular}{|l|c|c|l|}
\hline & PIH & Non-PIH & $\mathbf{n = 1 4 0}$ (No data available = 2) \\
\hline$\leq$ Cutoff & 5 & 8 & Positive predictive value, 38.5\% \\
\hline$>$ Cutoff & 1 & 124 & Negative predictive value, 99.2\% \\
\hline & Sensitivity, 83.3\% & Specificity, 93.9\% & \\
\hline
\end{tabular}

Odds ratio in which the $\mathrm{PIH}$ is present when the plasma prorenin concentration is under the cut-off level

Table 3b: Multivariate logistic regression analysis for prorenin (PR) and pregnancyinduced hypertension (PIH). 
might play a role as an angiogenesis factor (placental development) in pregnancy rather than as a BP modulator. The recent "twostage disorder" theory explains the pathogenesis of PIH. Early in normal pregnancy, extra villous cytotrophoblasts invade the uterine spiral arteries in the deciduas and myometrium, and these invasive cytotrophoblasts replace the endothelial layer of the maternal spiral arteries (i.e., spiral artery remodeling). This remodeling develops widecaliber low-resistance vessels, which provide a sufficient placental bed. The aforementioned theory explains that PIH results from poor placental development in which correct remodeling has failed $[8,11]$. $\mathrm{PR},(\mathrm{P}) \mathrm{RR}$, and angiotensin 1 regulate the placental angiogenesis through the vascular endothelial growth factor expression $[12,13]$. Low serum PR levels during the third trimester in association with PIH may be related to incomplete placental angiogenesis.

In fact, low serum PR levels may be a result rather than a cause of PIH. Serum PR levels might decrease compensatorily as a result of PIH. The pathogenesis and etiology between early-onset and late-onset PIH may be different: however, the number of PIH cases was not enough for statistical analysis. We plan to conduct a further study that measures serum $\mathrm{s}(\mathrm{P}) \mathrm{RR}$ and $\mathrm{PR}$ from the maternal and cord blood sample.

\section{References}

1. Sibai B, Dekker G, Kupferminc M (2005) Pre-eclampsia. Lancet 365: 785-799.

2. Gant NF, Daley GL, Chand S, Whalley PJ, MacDonald PC (1973) A study of angiotensin II pressor response throughout primigravid pregnancy. J Clin Invest 52: 2682-2689.

3. Chesley LC (1966) Vascular reactivity in normal and toxemic pregnancy. Clin Obstet Gynecol 9: 871-881.
4. Talledo OE (1966) Renin-angiotensin system in normal and toxemic pregnancies. I. Angiotensin infusion test. Am J Obstet Gynecol 96: 141-143.

5. Nguyen G, Delarue F, Burcklé C, Bouzhir L, Giller T, et al. (2002) Pivotal role of the renin/prorenin receptor in angiotensin II production and cellular responses to renin. J Clin Invest 109: 1417-1427.

6. Watanabe N, Bokuda K, Fujiwara T, Suzuki T, Mito A, et al. (2012) Soluble (pro)renin receptor and blood pressure during pregnancy: a prospective cohort study. Hypertension 60: 1250-1256.

7. Watanabe N, Morimoto S, Fujiwara T, Suzuki T, Taniguchi K, et al. (2013) Association between soluble (Pro)renin receptor concentration in cord blood and small for gestational age birth: a cross-sectional study. PLoS One 8: e60036.

8. Furuya M, Ishida J, Aoki I, Fukamizu A (2008) Pathophysiology of placentation abnormalities in pregnancy-induced hypertension. Vasc Health Risk Manag 4: 1301-1313.

9. Seki $H(2014)$ The role of the renin-angiotensin system in the pathogenesis of preeclampsia - new insights into the renin-angiotensin system in preeclampsia. Med Hypotheses 82: 362-367.

10. Japan Society for the Study of Toxemia of Pregnancy (2005) Historical perspective of study of pregnancy-induced hypertension in Japan. Medical View Co. Ltd., Tokyo, Japan: 76-81.

11. Pijnenborg R, Anthony J, Davey DA, Rees A, Tiltman A, et al. (1991) Placental bed spiral arteries in the hypertensive disorders of pregnancy. $\mathrm{Br} \mathrm{J}$ Obstet Gynaecol 98: 648-655.

12. Pringle KG, Tadros MA, Callister RJ, Lumbers ER (2011) The expression and localization of the human placental prorenin/renin-angiotensin system throughout pregnancy: roles in trophoblast invasion and angiogenesis? Placenta 32: 956-962.

13. Herr D, Rodewald M, Fraser HM, Hack G, Konrad R, et al. (2008) Regulation of endothelial proliferation by the renin-angiotensin system in human umbilical vein endothelial cells. Reproduction 136: 125-130. 